\title{
Pyrogen detection methods: Comparison of bovine whole blood assay (bWBA) and monocyte activation test (MAT)
}

\author{
Christian Wunderlich, Stephan Schumacher and Manfred Kietzmann*
}

\begin{abstract}
Background: Pyrogen detection is of utmost importance in pharmaceutical industry, laboratories and health care institutions. As an alternative to the animal-consuming rabbit pyrogen test or Limulus amoebocyte lysate test, the monocyte activation test was introduced as a gold standard method in the European Pharmacopoeia. However, the monocyte activation test has not gained wide acceptance in practice.

Methods: We stimulated bovine whole blood with different endotoxin preparations (lipopolysaccharide E.coli 0127: B8 and 0113:H10), as well as the non-endotoxin pyrogens peptidoglycan and lipoteichoic acid. Prostaglandin $\mathrm{E}_{2}\left(\mathrm{PGE}_{2}\right)$ served as read out.

Results: Employing $\mathrm{PGE}_{2}$ as read out enabled detection limits of $0.04 \mathrm{EU} / \mathrm{ml}$ for lipopolysaccharide $0127: \mathrm{B} 8,0.25 \mathrm{EU} / \mathrm{ml}$ for lipopolysaccharide 0113:H10 and $10 \mathrm{\mu g} / \mathrm{ml}$ of lipoteichoic acid as well as peptidoglycan. To evaluate the bWBA test system as a possible alternative to the MAT we performed a peer-to-peer comparison of the two methods and confirmed similar sensitivities.
\end{abstract}

Conclusions: In conclusion, the bovine whole blood assay (bWBA) reproducibly enabled sensitive detection of endotoxin and non-endotoxin pyrogens and may thus become a viable alternative for pyrogen testing.

Keywords: Endotoxin, Bovine whole blood, Prostaglandin E $E_{2}$ Pyrogen, Monocyte activation test, Lipopolysaccharide, Lipoteichoic acid

\section{Background}

The detection of pyrogenic contamination is an essential part of drug safety testing in the pharmaceutical industry, reference laboratories as well as health care institutions. To guarantee patient safety, critical threshold levels of pyrogenic contamination have been determined and must not be exceeded. Therefore the European Pharmacopoeia (EP) promotes the monocyte activation test (MAT) as most suitable test for pyrogen testing [1]. Former methods, the rabbit pyrogen test (RPT) [2] and the Limulus amoebocyte lysate (LAL) test [3] are limited by inherent disadvantages since the RPT has a comparably low sensitivity for pyrogens [4] and the LAL is unable to detect non-endotoxin pyrogens [5]. Moreover, both are animal-consuming tests

\footnotetext{
* Correspondence: Manfred.Kietzmann@tiho-hannover.de University of Veterinary Medicine Hannover, Foundation, Institute of Pharmacology, Toxicology and Pharmacy, Bünteweg 17, Hannover 30559,
} Germany

which, according to the $3 \mathrm{R}$ concept - replacement, reduction, refinement - , should be avoided [6-8].

Nevertheless, product safety has to remain the first priority of medical product legislation, while economic considerations are also important to the industry and suitable methods need to offer a reasonable cost-benefit ratio. The MAT utilizes human blood $[9,10]$ and is characterized by a high sensitivity for detecting endotoxin and non-endotoxin pyrogens. However, apparently it did not satisfy the needs of the pharmaceutical industry because it has not been widely used since its introduction in 2010 . This might be partly due to the fact that accessing fresh human whole blood or producing large amounts of cryoblood of uniform quality for use in the MAT is certainly a logistic challenge. According to the European Pharmacopoeia, blood donors must confirm that they have been free of signs of infection and have not taken anti-inflammatory medications for one week before 
donation [1]. Additionally, commercialized cryoblood is routinely tested for sterility and HIV, HAV, HCV and HBV [11]. However, there remain several potentially influencing factors that cannot be standardized in a human-based test system since lifestyle and genetic background certainly differ significantly between donors.

In principal, if blood from a large animal species and a designated breed would be used for pyrogen detection most of these limitations could be overcome, because the animals can be housed under standardized specific pathogen-free conditions. Several aspects favor the use of bovine blood, for instance the fact that the Toll-like receptor equipment of bovine leukocytes is comparable to humans [12] as well as reports suggesting the suitability of bovine blood for the detection of lipopolysaccharides (LPS) [13].

In a previous study we reported that bovine whole blood can be used for a sensitive detection of LPS 0111:B4 from E.coli by using Prostaglandin $\mathrm{E}_{2}$ as readout [14]. In the present study we investigated whether the system we established was also capable of detecting other endotoxins and gram-positive cell wall components. Additionally, we compared our method with the commercially available PyroDetect System (MAT) in a peer-to-peer setup.

\section{Methods}

\section{Used stimulants}

Endotoxin derived from Escherichia coli 0127:B8 (L3129, Sigma-Aldrich, Steinheim, Germany; stock $\geq 500000$ $\mathrm{EU} / \mathrm{mg}$ ), WHO standard endotoxin from Escherichia coli 0113:H10:K (10 000 IU per vial, Merck, Darmstadt, Germany), peptidoglycan from Bacillus subtilis (low endotoxin, $\leq 1 \mathrm{EU} / \mathrm{mg}$, InvivoGen, Toulouse, France) and lipoteichoic acid from Staphylococcus aureus (low endotoxin, $\leq 1 \mathrm{EU} / \mathrm{mg}$, InvivoGen) were used as stimulants. Solutions were prepared with LAL-water or pyrogen-free saline. Aliqouts were stored at $-20^{\circ} \mathrm{C}$, except for the WHO Endotoxin, which was stored at $-80^{\circ} \mathrm{C}$. Immediately prior to use the aliquots were thawed, sonicated and diluted with pyrogen-free saline into different concentrations. Concentrations used for LPS 0127:B8 were 0.039, $0.078,0.156,0.313,0.625$ and $1.25 \mathrm{EU} / \mathrm{ml}$, for LPS 0113: $\mathrm{H} 10 \mathrm{0.063}, 0.125,0.25,0.5,1$ and $2 \mathrm{EU} / \mathrm{ml}$. Peptidoglycan and lipoteichoic acid were diluted to 1, 10, 50, 100 and $1000 \mu \mathrm{g} / \mathrm{ml}$.

\section{Blood collection and ethical statement}

Blood was obtained via venipuncture from healthy cattle (mainly Holsteins except two crossbreds and one red Holstein) into $7.5 \mathrm{ml}$ heparinized tubes (Li-Heparin, 19 IU/ml, SARSTEDT Monovette, Nümbrecht, Germany). The animals were owned by and stabled in the Clinic for Cattle of the University of Veterinary Medicine Hannover, Foundation. All blood donors were female, non-lactating cows and were fed with hay ad libitum. The age ranged from 2.5 to 13 years.

This study received ethical approval by the Lower Saxony State Office for Consumer Protection and Food Safety (LAVES), Oldenburg (Az. 33.9-42502-05-13A361). All procedures involving animals were carried out in accordance with German legislation on animal welfare.

\section{In vitro assay using bovine peripheral blood}

$225 \mu \mathrm{l}$ lithium heparin blood from different donors were pipetted into 96-well cell culture plates (SARSTEDT, Nümbrecht, Germany) and stimulated for 24 hours with $25 \mu \mathrm{l}$ pyrogen solution or vehicle. After incubation at $37^{\circ} \mathrm{C}$ and $5 \% \mathrm{CO}_{2}$, the 96 -well plates were centrifuged at $2272 \times \mathrm{g}$ for 10 minutes, the supernatants were collected and frozen at $-80^{\circ} \mathrm{C}$ until analysis. $\mathrm{PGE}_{2}$ concentration was determined using the Cayman Prostaglandin $\mathrm{E}_{2}$ Express EIA Kit (Cayman Chemical Company, Ann Arbor, MI, USA) following the manufacturer's instructions.

\section{Comparison with the PyroDetect system}

The PyroDetect System (Merck, Darmstadt, Germany) was used according to the manufacturer's instructions as a quantitative test with the exception that samples were not tested at different dilutions. The quantitative test is described by the producers as method A. By using method $A$, a quantitative comparison of the samples with the standard endotoxin is possible. In summary, the stimulating agents were pipetted as $20 \mu \mathrm{l}$ portions into the 96-well plate (included in the kit) under a horizontal flow bench. Apart from the spike and blank wells - the former was filled with stimulant and spiked RPMI medium, the latter with a total of $40 \mu \mathrm{l}$ RPMI - $20 \mu \mathrm{l}$ RPMI were added to each well. The two cryo blood vials (included in the kit) were thawed in a water bath for 1 minute and diluted immediately with $8 \mathrm{ml}$ RPMI 1640 cell culture medium each (included in the kit). Afterwards the cryopreserved blood mixture was pipetted into the plate at a volume of $200 \mu \mathrm{l}$ per well. After incubation for 16 hours at $37^{\circ} \mathrm{C}$ with $5 \%$ $\mathrm{CO}_{2}$ the mixture in the wells was resuspended five times and transferred to the ELISA plate (included in the kit). The IL-1 $\beta$ ELISA was performed following the manufacturer's instructions. To compare this test system with the bovine whole blood assay the same stimulants (diluted in RPMI) were tested simultaneously using the blood of 6 animals (separately) following the method described before.

\section{Statistical analysis}

Statistical analysis was carried out using the software SAS 9.3 (SAS, Cary, NC, USA). Data were checked for normal distribution by visual inspection and the Kolmogorov-Smirnov test. Some data sets showed a left-skewed distribution and failed the normality test. Therefore a permutation test (10000 permutations) was 
used for calculating a randomized complete block design (equivalent to exact Friedmann Test) and $\mathrm{P}$ values smaller 0.05 were considered significant. Calculations were done with the SAS macro RIBDPERM.MAC (provided by Erich Schumacher, Institut für Angewandte Mathematik und Statistik, Universität Hohenheim). Data are represented as box-plot with median and min to max whiskers.

\section{Results}

\section{Pyrogen stimulation}

LPS from E.coli 0127:B8 was used as a stimulating agent and we found a dose-dependent increase of $\mathrm{PGE}_{2}$ starting at a dose of $0.08 \mathrm{EU} / \mathrm{ml}$ and reaching a plateau at 0.16 $\mathrm{EU} / \mathrm{ml}$ (Figure 1). Using the WHO standard endotoxin (LPS E.coli 0113:H10) we discovered a dose-dependent increase of $\mathrm{PGE}_{2}$ release starting at $0.25 \mathrm{EU} / \mathrm{ml}$ (Figure 2). Peptidoglycan (PGN) from Bacillus subtilis induced a dose-dependent increase of $\mathrm{PGE}_{2}$ in concentrations of more than $10 \mu \mathrm{g} / \mathrm{ml}$ (Figure 3). Likewise, lipoteichoic acid (LTA) from Staphylococcus aureus provoked a significant increase of $\mathrm{PGE}_{2}$ at concentrations of $10 \mu \mathrm{g} / \mathrm{ml}$ and above $(1 \mu \mathrm{g} / \mathrm{ml}$ provoked an increase as well, but fell just short of the level of significance, $\mathrm{p}=0.056$ ). The maximum $\mathrm{PGE}_{2}$ production was seen at $50 \mu \mathrm{g} / \mathrm{ml}$, but although eicosanoid release elicited by higher LTA concentrations declined, it remained significantly higher compared to unstimulated blood (Figure 4).

\section{Bovine whole blood assay compared to PyroDetect system}

After 16 hours of stimulation - analogously to the manufacturer's lab procedure - the PyroDetect System ELISA detected the presence of $0.25 \mathrm{EU} / \mathrm{ml}$ standard

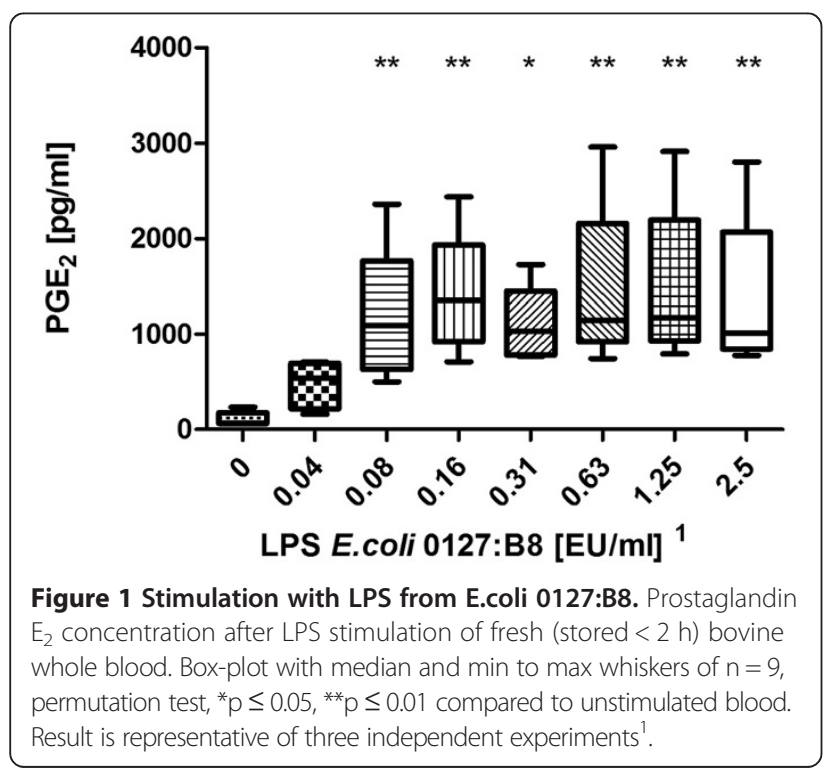

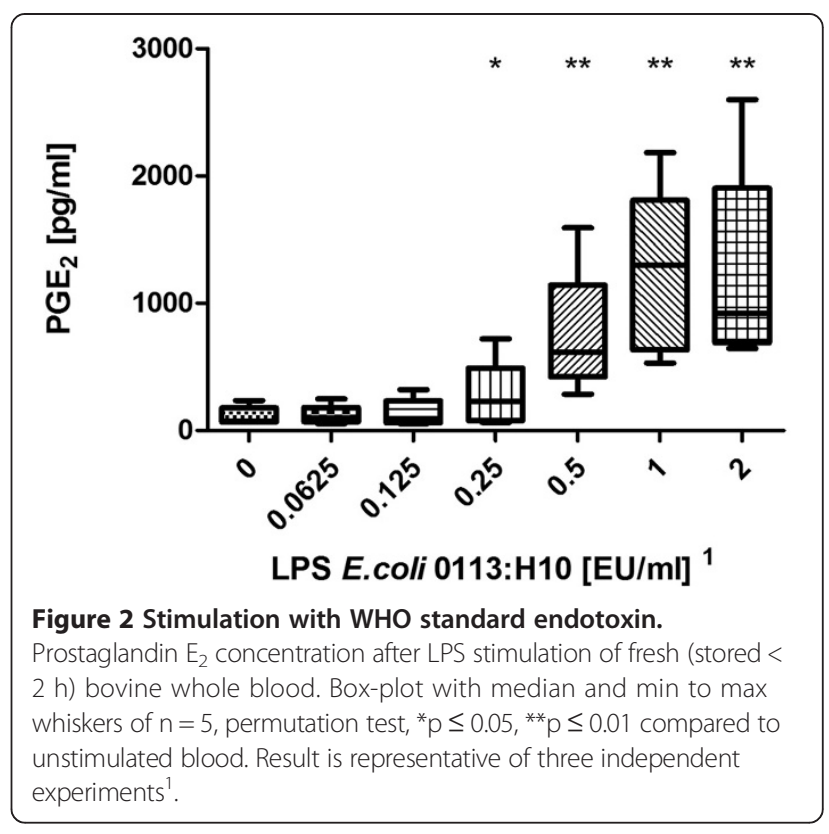

endotoxin (Figure 5), whereas $0.0625 \mathrm{EU} / \mathrm{ml}$ and 0.125 $\mathrm{EU} / \mathrm{ml}$ did not induce measurable cytokine production. Importantly, the PyroDetect System also detected the presence of all other pyrogens at all concentrations used. Unfortunately, the color reaction of the ELISA was so intense that we were unable to quantify it thus precluding the specification of EU equivalents.

The simultaneous stimulation of bovine blood from 6 animals with the same pyrogens resulted in detection limits comparable to those obtained from the previous experiments. Results of one animal were excluded from analysis because of preexisting $\mathrm{PGE}_{2}$ release from the

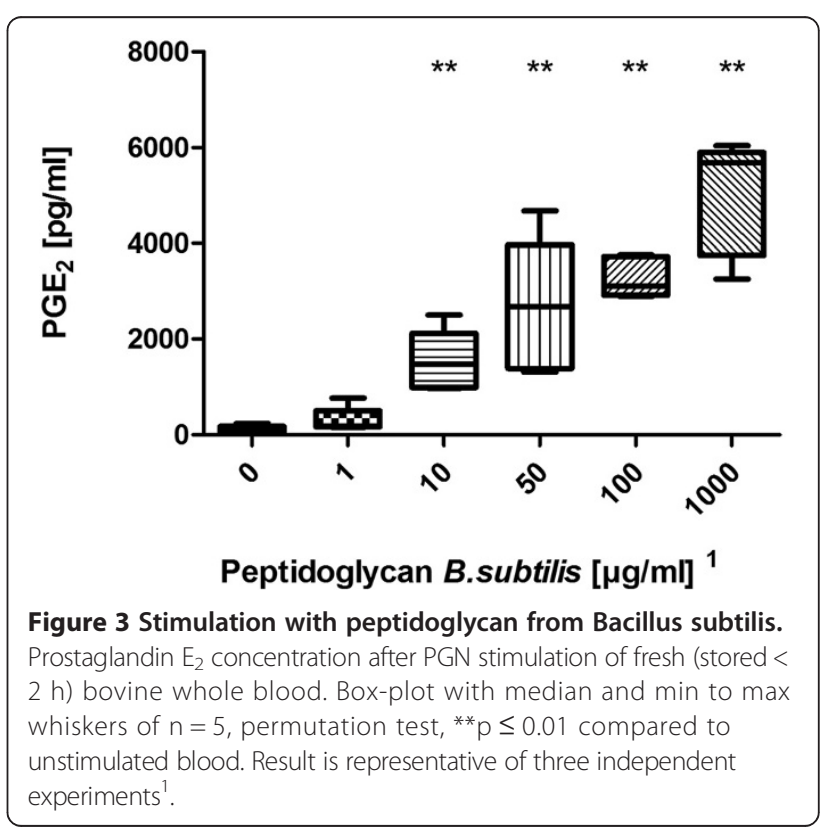




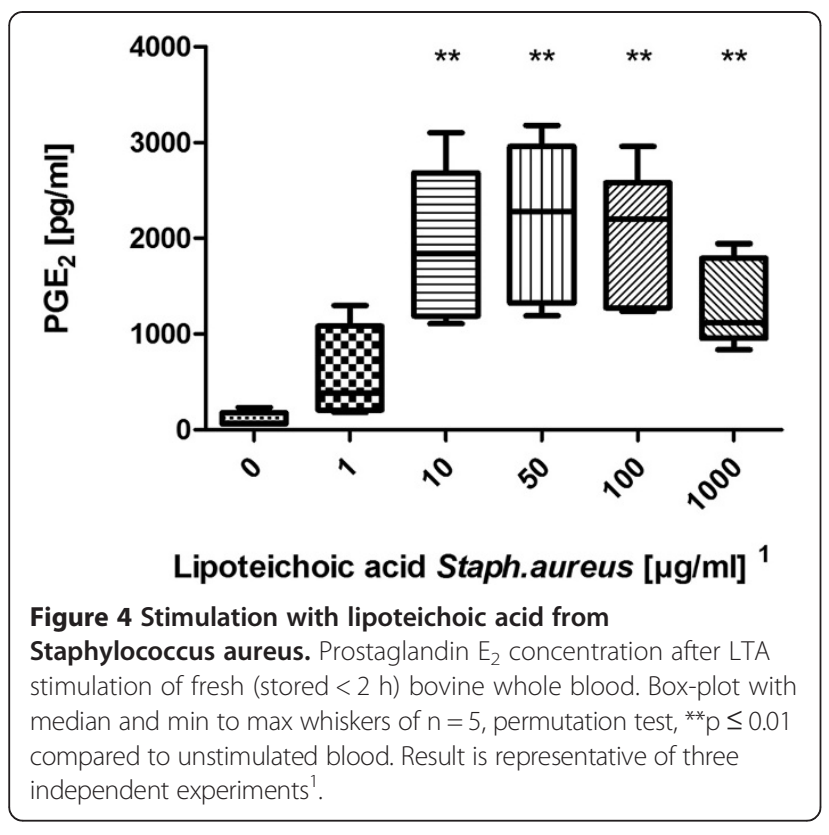

unstimulated blood. The comparative detection limits of the two test methods are given in Table 1.

\section{Discussion}

We have previously shown that LPS 0111:B4 from E.coli can be reliably detected using a bovine whole blood assay and $\mathrm{PGE}_{2}$ as readout [14]. Hartung and Wendel [15] reported the suitability of a test method utilizing human whole blood for the detection of endotoxin as well as non-endotoxin pyrogens. The quite similar tolllike receptor (TLR) equipment of human and bovine leukocytes [12] gave reason to expect the same would be

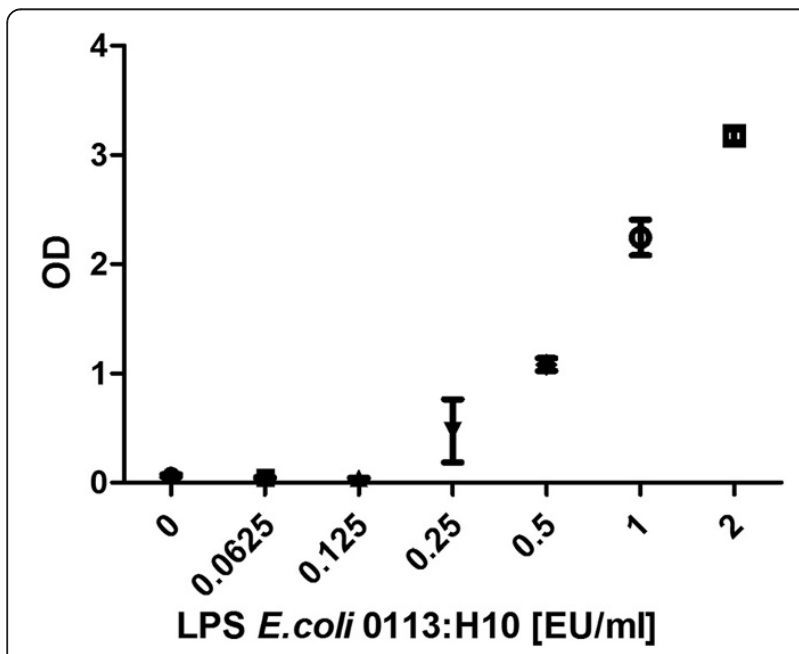

Figure 5 PyroDetect System standard curve. PyroDetect System WHO standard endotoxin calibration curve, optical density in relation to LPS concentration. Mean with SEM of pooled cryoconserved human blood in 4 measurements. possible using our test system. Thus, we decided to investigate whether the bovine whole blood assay was capable of detecting a broad range of pyrogens with the required sensitivity.

\section{Detection of LPS}

The bWBA was capable of detecting the presence of two different kinds of endotoxins. Remarkably, the detection of LPS 0127:B8 was $3-6$ fold more sensitive than the detection of LPS 0113:H10 (0.04 - $0.08 \mathrm{EU} / \mathrm{ml}$ vs. $0.25-$ $0.5 \mathrm{EU} / \mathrm{ml}$ ) which was confirmed using the PyroDetect System. Similar findings were reported by others who showed an up to 1000 -fold difference in potency of different endotoxins $[16,17]$. However, the observed detection limits of both test systems for the WHO standard endotoxin (LPS E.coli 0113:H10) still complied with the specifications of the MAT and the required sensitivity of pyrogen testing of $0.5 \mathrm{EU} / \mathrm{ml}$ [1].

\section{Detection of PGN}

The bWBA was capable of detecting $10-50 \mu \mathrm{g} / \mathrm{ml}$ PGN. It is still a matter of controversy how the stimulatory potency of PGN is conveyed. Although it has long been thought to be an agonist of the TLR2, PGN is probably sensed by the nucleotide-binding oligomerization domaincontaining proteins (NOD) 1 and 2 [18]. Moreover, it has been reported that commercial PGN preparations are often contaminated with endotoxin [19] and highly purified PGN was unable to stimulate cytokine release in a human whole blood test system [20,21]. This issue was also discussed in a meta-analysis of Rockel and Hartung [22] and to date there is no evidence that highly purified PGN is an immune stimulant. In order to prevent the effects of a potential endotoxin contamination we used a PGN preparation from Invivogen. This manufacturer guarantees an endotoxin content of less than 1 EU per milligram. Regarding that in our study detectable LPS concentrations were in the $\mathrm{pg} / \mathrm{ml}$ range, whereas non-endotoxin pyrogens could be detected in the $\mu \mathrm{g} / \mathrm{ml}$ range a falsification of the results due to LPS contamination should be unlikely although it cannot be completely excluded.

\section{Detection of LTA}

The bWBA was capable of detecting $10 \mu \mathrm{g} / \mathrm{ml}$ LTA. Interestingly, we observed a decrease of $\mathrm{PGE}_{2}$ release at the highest concentrations of LTA, a finding which has not been reported in the literature so far. A possible explanation could be a complex formation of LTA at high concentrations [23], a phenomenon that seems to occur because of the intermolecular interactions of LTA molecules. Another explanation could be an enhanced binding by the bovine scavenger receptor type 1 [24], which has the ability to interact with or bind, for example, 
Table 1 Detection limits of the different stimulants

\begin{tabular}{|c|c|c|c|c|}
\hline & \multicolumn{4}{|c|}{ Detection limits } \\
\hline & Experiment 1 & Experiment 2 & Experiment 3 & PyroDetect System \\
\hline & $n=6-9$ & $\mathrm{n}=6$ & $\mathrm{n}=5$ & Poolblood \\
\hline LPS E.coli & \multirow{2}{*}{$0.08 \mathrm{EU} / \mathrm{ml}$} & \multirow[b]{2}{*}{$0.04 \mathrm{EU} / \mathrm{ml}$} & \multirow[b]{2}{*}{$0.08 \mathrm{EU} / \mathrm{ml}$} & \multirow[b]{2}{*}{$0.04 \mathrm{EU} / \mathrm{ml} \neq$} \\
\hline 0127:B8 & & & & \\
\hline LPS E.coli & \multirow{2}{*}{ not tested } & \multirow{2}{*}{$0.5 \mathrm{EU} / \mathrm{ml}$} & \multirow{2}{*}{$0.25 \mathrm{EU} / \mathrm{ml}$} & \multirow[b]{2}{*}{$0.25 \mathrm{EU} / \mathrm{ml}$} \\
\hline 0113:H10 & & & & \\
\hline Peptidoglycan & \multirow{2}{*}{$10 \mu \mathrm{g} / \mathrm{ml}$} & \multirow{2}{*}{$50 \mu \mathrm{g} / \mathrm{ml}$} & \multirow{2}{*}{$10 \mu \mathrm{g} / \mathrm{ml}$} & \multirow{2}{*}{$1 \mu \mathrm{g} / \mathrm{ml} \neq$} \\
\hline Bac. subtilis & & & & \\
\hline Lipoteichoic acid & \multirow[b]{2}{*}{$10 \mu \mathrm{g} / \mathrm{ml}$} & \multirow[b]{2}{*}{$10 \mu \mathrm{g} / \mathrm{ml}$} & \multirow[b]{2}{*}{$10 \mu \mathrm{g} / \mathrm{ml}$} & \multirow[b]{2}{*}{$1 \mu \mathrm{g} / \mathrm{ml} \neq$} \\
\hline Staph. aureus & & & & \\
\hline
\end{tabular}

Different animals were used, permutation test, compared to unstimulated blood. Experiment 3 was the comparison with the PyroDetect System. $\neq=$ lowest concentration tested.

pyrogens. However, it remains unclear why this did not seem to apply to PGN. Yet, despite the decline of $\mathrm{PGE}_{2}$, the high concentrations of LTA still remained detectable and concentrations above $100 \mu \mathrm{g} / \mathrm{ml}$ are very unlikely to occur in pyrogen-contaminated medicinal products.

A meta-analysis by Rockel and Hartung discussed LTA as a possible reference stimulant for grampositive bacteria, analogous to endotoxin for gramnegative bacteria [22]. Similar to PGN some commercial LTA preparation have been reported to be contaminated by LPS [25], so again we used a preparation from Invivogen to reduce the risk of false positive results. Nevertheless, it is not clear whether LTA itself is a pyrogen or not. Zähringer et al. [18] elegantly elucidated how contaminating lipopetides like MALP-2 likely explain the TLR2-stimulating effects of LTA and PGN preparations. A TLR2-agonistic activity of natural and synthetic lipopeptides has also been confirmed by others [26].

\section{Comparison of the MAT and bWBA}

In order to compare the sensitivity of the bovine whole blood assay with the commercially available PyroDetect System we decided to perform a peer-to-peer comparison with the same stimulants. The comparison of the two methods resulted in the same detection level of WHO standard endotoxin, $0.25 \mathrm{EU} / \mathrm{ml}$ - sufficing the postulated allowed level of $0.5 \mathrm{EU} / \mathrm{ml}$ in pharmaceutical products [1]. With regard to PGN, LTA and LPS 0127:B8 the PyroDetect System appeared to be more sensitive. It was capable of identifying the presence of $1 \mu \mathrm{g} / \mathrm{ml}$ PGN or LTA (the lowest concentrations used in our experiments) and other studies suggest that the MAT can detect concentrations as low as $100 \mathrm{ng} / \mathrm{ml}$ LTA [25,27]. The human blood-based MAT has been validated for endotoxin detection but there was no formal evaluation study with respect to non-endotoxin pyrogen detection [22]. However, Hasiwa et al. [28] strongly suggested that the MAT is able to detect non-endotoxin pyrogens and whether a formal validation is necessary is beyond the scope of this discussion.

The inferior performance of the bovine assay in terms of non-endotoxin pyrogens may indicate a shortcoming. The difference in sensitivity of the two methods may partly be due to the different endpoints used. As an acute phase protein IL-1 $\beta$ is produced by blood cells only in response to potentially dangerous exogenous stimuli, e.g. pyrogens [29] resulting in a strong increase of its concentration. In contrast, certain endogenous levels of $\mathrm{PGE}_{2}$ are physiologically present in (bovine) blood. Therefore, interindividual differences in basal plasma levels demanded a quite distinct increase of eicosanoid production in order to be statistically significant. Unfortunately, we were unable to obtain a commercial kit suitable for the determination of cytokines in bovine whole blood [14]. Future investigations will need to clarify whether the bWBA can be optimized in order to increase its sensitivity, but the fact that the level of significance was just barely missed after stimulation with $1 \mu \mathrm{g} / \mathrm{ml}$ LTA seems promising.

Some medicinal products like vaccines may benefit from in vitro pyrogen testing in the target species. Bacterial vaccines contain bacterial components by definition and different species may display differing sensitivities towards certain bacteria [30]. Thus, testing vaccines in the target species may increase product safety. Considering the diversity of veterinary species it will, however, be very difficult to test every product in the target species, especially because many human medicinal products (with the exception of vaccines) are used off-label in veterinary medicine. With that said, pyrogen testing using qualitycontrolled blood from cattle housed under standardized conditions may be an option with favorable risk/benefitratio.

\section{Conclusions}

With regard to the aim of reduction, refinement and replacement (3R) of animal experiments the introduction 
of the MAT seemed promising for the reduction of the use of RPT and LAL [31]. However, this objective does not seem to have been achieved because the MAT is not widely used yet. Here we show the potential of detecting endotoxin and non-endotoxin pyrogens using a bovine whole blood assay. Further efforts are indispensable to improve the method's functionality, detection limits and robustness as well as to verify whether it can detect further pyrogens including lipopeptides. If the bWBA meets these requirements it should be possible to produce large standardized batches of bovine blood in reference laboratories which could then offer pyrogen testing services using the bWBA as an alternative to the RPT.

\section{Endnote}

${ }^{1}$ Notably, concentrations in the figures refer to the stimulant solutions used. These were diluted tenfold in the final setup (using $225 \mu \mathrm{l}$ whole blood and $25 \mu \mathrm{l}$ stimulant). Results depicted in the figures are representative of repeated experiments. The detection limits from all experiments are presented in Table 1.

\section{Abbreviations \\ bWBA: Bovine whole blood assay; MAT: Monocyte activation test; RPT: Rabbit pyrogen test; LAL: Limulus amoebocyte lysast test; EP: European pharmacopoeia; LPS: Lipopolysaccharid; PGN: Peptidoglycan; LTA: Lipoteichoic acid; PGE 2 : Prostaglandin $E_{2}$; E.coli: Escherichia coli; WHO: World health organization; TLR: Toll-like receptor; EU: Endotoxin unit; NOD: Nucleotide oligomerization domain; MALP-2: Macrophage-activating lipopeptide 2.}

\section{Competing interests}

The authors declare that they have no competing interests.

\section{Authors' contributions}

CW, SS and MK conceived and designed the study. CW performed the experiments, CW and SS analysed the data and wrote the manuscript, MK contributed valuable discussion and critically revised the article. MK had full access to the data and is the guarantor of the study. All authors read and approved the final manuscript.

\section{Acknowledgments}

We thank the Clinic for Cattle, University of Veterinary Medicine Hannover Foundation, especially to Dr. Kathrin Herzog and Prof. Dr. Jürgen Rehage for their excellent support in obtaining the bovine blood samples. We also gratefully acknowledge the help of Dr. Karl Rohn who provided assistance with the statistical analysis (Institute for Biometry, Epidemiology and Information Processing (IBEI), University of Veterinary Medicine Hannover, Foundation).

Received: 26 May 2014 Accepted: 4 September 2014 Published: 10 September 2014

\section{References}

1. EDQM: Europäisches Arzneibuch. Stuttgart: 7. Aufl., Deutscher Apotheke Verlag; 2011

2. Weary M, Wallin R: The rabbit pyrogen test. Lab Anim Sci 1973, 23:677-681.

3. Levin J, Bang FB: The role of endotoxin in the extracellular coagulation of limulus blood. Bull Johns Hopkins Hosp 1964, 115:265-274.

4. Weigandt M: Der Humane Vollblut-Pyrogentest-Optimierung, Validierung und Vergleich mit den Arzneibuchmethoden. Diss: Univ. Heidelberg, Med.Fak; 2001

5. Fennrich S, Fischer M, Hartung T, Lexa P, Montag-Lessing T, Sonntag HG, Weigandt $M$, Wendel A: Detection of endotoxins and other pyrogens using human whole blood. Dev Biol Stand 1999, 101:131-139.
6. Russell W, Burch R: The Principles of Humane Experimental Technique. London, UK: Methuen; 1959.

7. Guhad F: Introduction to the 3Rs (Refinement, Reduction and Replacement). J Am Assoc Lab Anim Sci 2005, 44:58-59.

8. Gruber FP, Hartung T: Alternatives to animal experimentation in basic research. ALTEX 2004, 21(Suppl 1):3-31.

9. Schindler S, Asmus S, Von Aulock S, Wendel A, Hartung T, Fennrich S: Cryopreservation of human whole blood for pyrogenicity testing. J Immunol Methods 2004, 294:89-100.

10. Charton E, Brügger P, Spreitzer I, Golding B: Alternatives to animal testing In EDQM Symposium; 16.09.2011. Strasbourg, France: EDQM, Council of Europe; 2011.

11. MERCK: PyroDetect Cryoblood Artikel-Nr. 1.44155.0001. Darmstadt, Germany: Merck KGaA; 2014

12. McGuire K, Jones M, Werling D, Williams JL, Glass EJ, Jann O: Radiation hybrid mapping of all 10 characterized bovine Toll-like receptors. Anim Genet 2006, 37:47-50.

13. Imamura $S$, Nakamizo M, Kawanishi M, Nakajima N, Yamamoto K, Uchiyama M, Hirano F, Nagai H, Kijima M, Ikebuchi R, Mekata H, Murata S, Konnai S, Ohashi K: Bovine whole-blood culture as a tool for the measurement of endotoxin activities in Gram-negative bacterial vaccines. Vet Immunol Immunopathol 2013, 153:153-158.

14. Wunderlich C, Schumacher S, Kietzmann M: Prostaglandin E2 as a read out for endotoxin detection in a bovine whole blood assay. J Vet Pharmacol Ther 2014, ePub ahead of print. doi:10.1111/jvp.12148.

15. Hartung $T$, Wendel A: Die Erfassung von Pyrogenen in einem humanen Vollblutmodell. ALTEX 1995, 12:70-75.

16. Dehus O, Hartung T, Hermann C: Endotoxin evaluation of eleven lipopolysaccharides by whole blood assay does not always correlate with Limulus amebocyte lysate assay. J Endotoxin Res 2006, 12:171-180.

17. Hasiwa M, Kullmann K, Von Aulock S, Klein C, Hartung T: An in vitro pyrogen safety test for immune-stimulating components on surfaces. Biomaterials 2007, 28:1367-1375.

18. Zähringer $U$, Lindner $B$, Inamura $S$, Heine $H$, Alexander C: TLR2-promiscuous or specific? A critical re-evaluation of a receptor expressing apparent broad specificity. Immunobiology 2008, 213:205-224.

19. Li H, Nooh MM, Kotb M, Re F: Commercial peptidoglycan preparations are contaminated with superantigen-like activity that stimulates IL-17 production. J Leukoc Biol 2008, 83:409-418.

20. Travassos LH, Girardin SE, Philpott DJ, Blanot D, Nahori M-A, Werts C, Boneca IG: Toll-like receptor 2-dependent bacterial sensing does not occur via peptidoglycan recognition. EMBO Rep 2004, 5:1000-1006.

21. Rockel C, Hartung T, Hermann C: Different Staphylococcus aureus whole bacteria mutated in putative pro-inflammatory membrane components have similar cytokine inducing activity. Immunobiology 2011, 216:316-321.

22. Rockel C, Hartung T: Systematic review of membrane components of Gram-positive bacteria responsible as pyrogens for inducing human monocyte/ macrophage cytokine release. Front Pharmacol 2012, 3:56.

23. Ofek I, Simpson WA, Beachey EH: Formation of molecular complexes between a structurally defined $\mathrm{M}$ protein and acylated or deacylated lipoteichoic acid of streptococcus pyogenes. J Bacteriol 1982, 149:426-433.

24. Dunne DW, Resnick D, Greenberg J, Krieger M, Joiner KA: The type I macrophage scavenger receptor binds to gram-positive bacteria and recognizes lipoteichoic acid. Proc Natl Acad Sci U S A 1994, 91:1863-1867.

25. Kimbrell MR, Warshakoon H, Cromer JR, Malladi S, Hood JD, Balakrishna R, Scholdberg TA, David SA: Comparison of the immunostimulatory and proinflammatory activities of candidate Gram-positive endotoxins, lipoteichoic acid, peptidoglycan, and lipopeptides, in murine and human cells. Immunol Lett 2008, 118:132-141

26. Barrenschee M, Lex D, Uhlig S: Effects of the TLR2 agonists MALP-2 and Pam3Cys in isolated mouse lungs. PloS one 2010, 5:e13889.

27. Holtkamp B, Schmitz G, Hartung T: In vitro Pyrogentest Nachweis eines breiten Pyrogenspektrums im Monozyten-Aktivierungstest. B/Ospektrum 2010, 07/10, 16. Jahrgang: 779-782

28. Hasiwa N, Daneshian M, Bruegger P, Fennrich S, Hochadel A, Hoffmann S, Rivera-Mariani FE, Rockel C, Schindler S, Spreitzer I, Stoppelkamp S, Vysyaraju $K$, Hartung T: Evidence for the detection of non-endotoxin pyrogens by the whole blood monocyte activation test. ALTEX 2013, 30:169-208.

29. Daneshian M, Von Aulock S, Hartung T: Assessment of pyrogenic contaminations with validated human whole-blood assay. Nat Protoc 2009, 4:1709-1721. 
30. Usui M, Nagai $H$, Tamura Y: An in vitro method for evaluating endotoxic activity using prostaglandin $\mathrm{E}(2)$ induction in bovine peripheral blood. Biologicals 2013, 41:158-161.

31. Fennrich S, Fischer M, Hartung T, Lexa P, Montag-Lessing T, Sonntag HG, Weigandt $\mathrm{M}$, Wendel A: [Evaluation and further development of a pyrogenicity assay based on human whole blood]. ALTEX 1998, 15:123-128.

doi:10.1186/2050-6511-15-50

Cite this article as: Wunderlich et al:: Pyrogen detection methods:

Comparison of bovine whole blood assay (bWBA) and monocyte activation test (MAT). BMC Pharmacology and Toxicology 2014 15:50.

\section{Submit your next manuscript to BioMed Central and take full advantage of:}

- Convenient online submission

- Thorough peer review

- No space constraints or color figure charges

- Immediate publication on acceptance

- Inclusion in PubMed, CAS, Scopus and Google Scholar

- Research which is freely available for redistribution 